\title{
How long does it take patients to find a new primary care physician when theirs retires: a population-based, longitudinal study
}

Lindsay Hedden ${ }^{1 *}(\mathbb{D}$, Megan A. Ahuja², M. Ruth Lavergne1, Kimberlyn M. McGrail², Michael R. Law², Lucy Cheng ${ }^{2}$ and Morris L. Barer ${ }^{2}$

\begin{abstract}
Background: The retirement of a family physician can represent a challenge in accessibility and continuity of care for patients. In this population-based, longitudinal cohort study, we assess whether and how long it takes for patients to find a new majority source of primary care (MSOC) when theirs retires, and we investigate the effect of demographic and clinical characteristics on this process.

Methods: We used provincial health insurance records to identify the complete cohort of patients whose majority source of care left clinical practice in either 2007/2008 or 2008/2009 and then calculated the number of days between their last visit with their original MSOC and their first visit with their new one. We compared the clinical and sociodemographic characteristics of patients who did and did not find a new MSOC in the three years following their original physician's retirement using Chi-square and Fisher's exact test. We also used Cox proportional hazards models to determine the adjusted association between patient age, sex, socioeconomic status, location and morbidity level (measured using Johns Hopkins' Aggregated Diagnostic Groupings), and time to finding a new primary care physician. We produce survival curves stratified by patient age, sex, income and morbidity.
\end{abstract}

Results: Fifty-four percent of patients found a new MSOC within the first 12 months following their physician's retirement. Six percent of patients still had not found a new physician after 36 months. Patients who were older and had higher levels of morbidity were more likely to find a new MSOC and found one faster than younger, healthier patients. Patients located in more urban regional health authorities also took longer to find a new MSOC compared to those in rural areas.

Conclusions: Primary care physician retirements represent a potential threat to accessibility; patients followed in this study took more than a year on average to find a new MSOC after their physician retired. Providing programmatic support to retiring physicians and their patients, as well as addressing shortages of longitudinal primary care more broadly could help to ensure smoother retirement transitions.

Keywords: Physician retirement, Primary care, Workforce planning, Majority source of care, Access

*Correspondence: Lindsay.hedden@sfu.ca

${ }^{1}$ Faculty of Health Sciences, Simon Fraser University, Blusson Hall, Room 11300, 8888 University Drive, Burnaby, BC V5A 1S6, Canada

Full list of author information is available at the end of the article

\section{Background}

There are longstanding concerns about the potential impact of primary care physician retirements on patient access to and continuity of care, and on service supply more broadly [1-8]. While considerable research has been done on the services that older physicians provide original author(s) and the source, provide a link to the Creative Commons licence, and indicate if changes were made. The images or other third party material in this article are included in the article's Creative Commons licence, unless indicated otherwise in a credit line to the material. If material is not included in the article's Creative Commons licence and your intended use is not permitted by statutory regulation or exceeds the permitted use, you will need to obtain permission directly from the copyright holder. To view a copy of this licence, visit http://creativecommons.org/licenses/by/4.0/. The Creative Commons Public Domain Dedication waiver (http://creativeco mmons.org/publicdomain/zero/1.0/) applies to the data made available in this article, unless otherwise stated in a credit line to the data. 
as they age and transition out of the workforce [1, 2, 913], very little attention has been given to how physician retirement affects patients [7]. Existing work suggests that disruption to longitudinal relationships between patients and physicians has been associated with difficulty accessing care [14], emotional distress [14, 15], poorer health outcomes [8], and decreased use of downstream primary care services $[7,8]$.

In 2019, eighteen percent of British Columbians and $15 \%$ of Canadians overall stated that they did not have a regular source of primary care [16]. Existing research suggests that patients without a regular source of primary care are more likely to rely on walk-in clinics or emergency departments [17-19]. This has a negative effect on care continuity and coordination [19-23], and access to preventive services [24-26].

Physician retirements add an additional challenge, as they mean that some patients who have a regular source of care then lose it. In a recent survey of patients who were actively seeking a primary care physician, $20 \%$ of respondents reported that they were looking because their physician had either retired or moved [27]. While finding a family physician may not be a high priority for young, healthy patients, it is critical for many, particularly those who have chronic conditions that require regular monitoring [27]. Like the broader population of unattached patients, patients of retired physicians reported using walk-in clinics or emergency departments more frequently [28]. They also reported concerns about poor continuity and poor access to preventative care [28].

Many provincial medical associations and state medical boards have published guidelines and recommendations for physicians who are considering retiring from clinical practice (e.g., [15, 33-36]) These guidelines include notifying patients of their leave date, whether another physician is taking over their practice, or providing a list of physicians taking new patients in the clinic or community $[15,35,36]$. Physicians are concerned about the negative impact their retirement may have on their patients. Several studies have reported that a feeling of responsibility for their patients (concerns about what will happen to the patients after the physician retires) keeps many physicians in practice longer than might otherwise have been the case [37-42].

The possible effect of physician retirement on access to primary care services across Canada in general, and in British Columbia (BC) in particular, has received some academic and media attention [1-8]. This paper expands on this existing literature by examining the use of primary care services by patients whose primary care physician retires. We describe both the periods preceding and following the retirement. Our research objectives are: (1) to measure the amount of time it takes for patients to find a new primary care physician; and (2) to assess whether time to finding a new primary care physician is associated with specific clinical and sociodemographic characteristics.

\section{Methods \\ Approach}

For this population-based, retrospective cohort study, we used administrative physician fee-for-service payment data to identify a cohort of patients and their primary care physicians, determine which physicians retired over the study period, and examine primary care interactions for their patients before and following that retirement. We then compared primary care interactions with a cohort of patients whose physicians did not retire.

\section{Data sources}

Health care in Canada is primarily publicly funded (through a variety of tax revenues), and privately delivered. Most primary care physicians run clinics as independent, small businesses and bill provincial health insurance plans (e.g., British Columbia Medical Services Plan (MSP)) on a fee-for-service basis; however, alternative models of payment such as capitation are becoming increasingly common in some provinces (though not in BC) [43]. Primary care physicians in Canada serve a coordinating and gate-keeping function; patients require a referral from a primary care physician to see a specialist. $\mathrm{BC}$ is divided into five regional health authorities that are responsible for service delivery within their respective geographic regions.

We used the British Columbia (MSP) Consolidation file [44] to identify patients who were registered to receive MSP-insured services for the entire period of 2005/2006 through 2011/2012. The Consolidation file also contains basic patient demographic data including age, sex, regional health authority (region) of residence, and income quintile.

Using unique patient-level identifiers, we linked the Consolidation file data to the MSP Physician Payment Database [45], which is a record of all physician-patient interactions billed on a fee-for-service (FFS) basis. These interactions (visits) include any face-to-face consultation between a physician and patient regardless of location (e.g., urgent care or community clinic). We used this data source to identify the Majority Source of Care (MSOC) for each patient, defined as the physician who provided more than $50 \%$ of their primary care contacts. To calculate this measure, patients must have had a minimum of three primary care visits in a single calendar year. This was necessary to ensure more accurate assignment of physicians to patients; it also permitted us to focus on a population likely to be most affected by any changes 


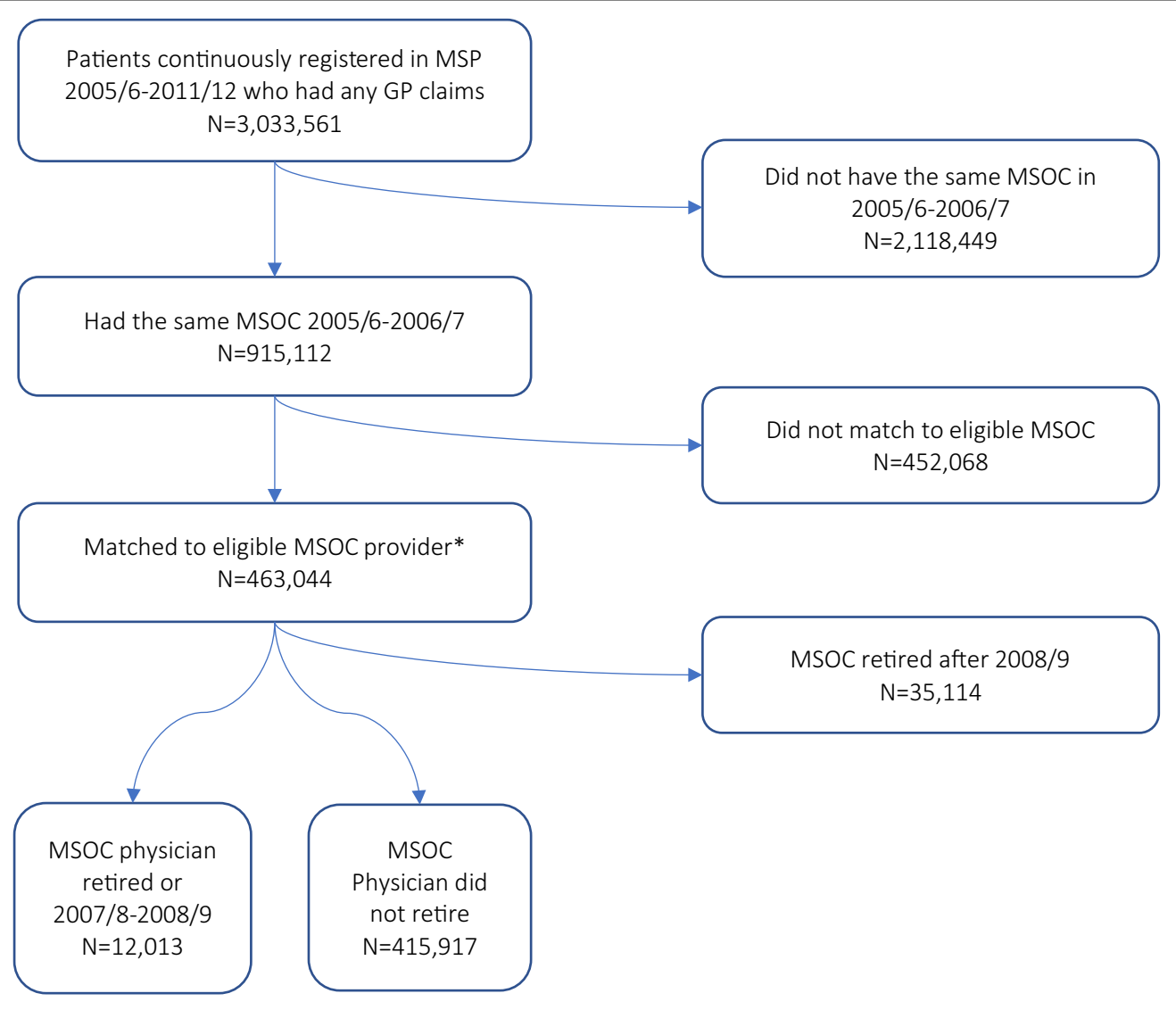

*Eligible MSOC provider: Aged 50+ in 2005/6, with an active practice license, and billing MSP in both of 2005/6 and 2006/7.

Fig. 1 Patient cohort selection

in primary care interactions surrounding retirement. We identified patients' MSOCs only for 2005/2006 and $2006 / 2007$ to avoid artificially limiting our sample to very high users.

We supplemented MSP FFS billings with data from the Alternative Payment Plan database, which tracks payments to physicians outside of the traditional FFS model. This allowed us to confirm that physicians who ceased billing MSP did in fact retire, rather than move to an alternative payment model.

We also used data from the MSP Physician Payment Database [45] and from hospital separations data [46] to quantify the level of morbidity for each patient, using Johns Hopkins Aggregated Diagnostic Groupings (ADGs). ADGs are generated using the International Classification of Diseases, 9th and 10th Revisions, diagnostic codes attached to specific health services utilization $[47,48]$. We focused on eight of 32 possible ADGs that are considered to be "major conditions" $[47,48]$.
Finally, we used data from the College of Physicians and Surgeons of BC physician registry [49] as a source for physician demographic data including age, sex, and training location (Canada or international) of each MSOC physician.

\section{Study cohort}

We included all individuals in $\mathrm{BC}$ who were continuously registered to receive MSP-insured services between 2005/2006 and 2011/2012, and who could be identified as having the same MSOC physician for 2005/2006 and 2006/2007. Patients with fewer than three visits annually were not assigned an MSOC and were therefore excluded.

Eligible physicians (i.e. those who might reasonably be considered as possible retirement candidates) were defined as those who were over age 50 in 2005/2006, had eligible practice licenses (i.e. did not practice out-ofprovince, opt out of public practice, or have their license 
Table 1 Patient cohort characteristics

\begin{tabular}{|c|c|c|c|c|}
\hline \multirow[t]{2}{*}{ Characteristic (in 2005/2006) } & \multicolumn{3}{|l|}{ Number (row \%) of individuals } & \multirow[t]{2}{*}{$P$ value } \\
\hline & $\begin{array}{l}\text { Patients with MSOC who retired } \\
(N=12,013)\end{array}$ & $\begin{array}{l}\text { Patients with MSOC who did not } \\
\text { retire }(N=415,917)\end{array}$ & Total & \\
\hline Age & & & & $<0.0001$ \\
\hline$<20$ & $527(4.4)$ & $32,606(7.8)$ & 33,133 & \\
\hline $20-29$ & $454(3.8)$ & $21,361(5.1)$ & 21,815 & \\
\hline $30-39$ & $832(6.9)$ & $37,098(8.9)$ & 37,930 & \\
\hline $40-49$ & $1884(15.7)$ & $70,052(16.8)$ & 71,936 & \\
\hline $50-59$ & $2915(24.3)$ & $92,378(22.2)$ & 95,293 & \\
\hline $60-69$ & $2569(21.4)$ & $76,481(18.4)$ & 79,050 & \\
\hline 70-79 & $1925(16.0)$ & $60,583(14.6)$ & 62,508 & \\
\hline $80+$ & $907(7.6)$ & $25,358(6.1)$ & 26,265 & \\
\hline Sex & & & & $<0.0001$ \\
\hline Female & $6548(54.5)$ & $236,570(56.9)$ & 243,118 & \\
\hline Male & $5460(45.5)$ & $179,186(43.1)$ & 184,646 & \\
\hline Unknown* & $\leq 5$ & $\leq 161$ & 166 & \\
\hline \multicolumn{5}{|l|}{ Socioeconomic status } \\
\hline 1-lowest & $2517(21.0)$ & $82,914(19.9)$ & 85,431 & $<0.0001$ \\
\hline 2 & $2450(20.4)$ & $85,796(20.6)$ & 88,246 & \\
\hline 3 & $2164(18.0)$ & $83,600(20.1)$ & 85,764 & \\
\hline 4 & $2267(18.9)$ & $79,805(19.2)$ & 82,072 & \\
\hline 5-highest & $2445(20.4)$ & $79,726(19.2)$ & 82,171 & \\
\hline Unknown & $170(1.4)$ & $4076(1.0)$ & 4246 & \\
\hline Health authority of residence & & & & $<0.0001$ \\
\hline Interior health & $2286(19.0)$ & $55,283(13.3)$ & 57,569 & \\
\hline Fraser health & $3056(25.4)$ & $151,886(36.5)$ & 154,942 & \\
\hline Vancouver coastal health & $2958(24.6)$ & $118,014(28.4)$ & 120,972 & \\
\hline Island health & $2948(24.5)$ & $73,747(17.7)$ & 76,695 & \\
\hline Northern health & $755(6.3)$ & $16,560(4.0)$ & 17,315 & \\
\hline Major ADGs & & & & 0.0005 \\
\hline 0 & $6253(52.1)$ & $224,315(53.9)$ & 230,568 & \\
\hline 1 & $3766(31.4)$ & $127,358(30.6)$ & 131,124 & \\
\hline 2 & $1418(11.8)$ & $45,866(11)$ & 47,284 & \\
\hline 3 & $429(3.6)$ & $13,744(3.3)$ & 14,173 & \\
\hline $4+$ & $147(1.2)$ & $4634(1.1)$ & 4781 & \\
\hline
\end{tabular}

*Precise numbers and percentages not included due to small cell counts (to preserve anonymity)

suspended), billed FFS during the study period, and were MSOC for at least one patient. We chose age 50 as the cut-off to ensure we were not mistakenly capturing physicians leaving practice for reasons other than retirement [50]. We defined retirement as a complete cessation of FFS and non-FFS (alternative payment plan) billings consistent with previously published work in this area [50, 51].

The data for both physicians and patients were stripped of identifiers, and then labeled with a unique study identifier in order to facilitate data set linkage and analysis without the risk of identification. The University of
British Columbia's Research Ethics Board granted ethics approval for this project and data linkage services were provided by Population Data BC. All inferences, opinions, and conclusions drawn in this manuscript are those of the authors, and do not reflect the opinions or policies of the Data Stewards.

\section{Outcomes}

Our main outcomes of interest were (1) whether or not patients whose MSOC retired in 2007/2008 or 2008/2009 found a new MSOC before the end of the study period; and (2) how long that process took. For each patient 
Table 2 Patients who found or did not find a new MSOC following their physician's retirement

\begin{tabular}{|c|c|c|c|c|}
\hline \multirow[t]{2}{*}{ Characteristic (in 2005/2006) } & \multicolumn{3}{|c|}{ Number (row \%) of individuals } & \multirow[b]{2}{*}{$P$ value } \\
\hline & $\begin{array}{l}\text { Patients who found new } \\
\text { MSOC } \\
N=11,377\end{array}$ & $\begin{array}{l}\text { Patients who did not find new } \\
\text { MSOC } \\
N=636\end{array}$ & $\begin{array}{l}\text { Total } \\
N=12,013\end{array}$ & \\
\hline \multicolumn{5}{|l|}{ Age } \\
\hline$<20$ & $408(3.6)$ & $119(18.7)$ & 527 & $<0.0001$ \\
\hline $20-29$ & $387(3.4)$ & $67(10.5)$ & 454 & \\
\hline $30-39$ & $739(6.5)$ & $93(14.6)$ & 832 & \\
\hline $40-49$ & $1755(15.4)$ & $129(20.3)$ & 1884 & \\
\hline $50-59$ & $2800(24.6)$ & $115(18.1)$ & 2915 & \\
\hline $60-69$ & $2512(22.1)$ & $57(9.0)$ & 2569 & \\
\hline 70-79 & $1896(16.7)$ & $29(4.6)$ & 1925 & \\
\hline $80+$ & $880(7.7)$ & $27(4.3)$ & 907 & \\
\hline Sex & & & & $p=0.0016$ \\
\hline Female & $6242(54.9)$ & $306(48.1)$ & 6548 & \\
\hline Male & $5131(45.1)$ & $329(51.7)$ & 5460 & \\
\hline Unknown* & $\leq 5$ & $\leq 5$ & $\leq 5$ & \\
\hline Socioeconomic status & & & & $<0.0001$ \\
\hline 1-lowest & $2334(20.5)$ & $183(28.8)$ & 2517 & \\
\hline 2 & $2327(20.5)$ & $123(19.3)$ & 2450 & \\
\hline 3 & $2061(18.1)$ & $103(16.2)$ & 2164 & \\
\hline 4 & $2157(19.0)$ & $110(17.3)$ & 2267 & \\
\hline 5-highest & $2341(20.6)$ & $104(16.4)$ & 2445 & \\
\hline Unknown & $157(1.4)$ & $13(2.0)$ & 170 & \\
\hline Major ADGs & & & & $<0.0001$ \\
\hline 0 & $5851(51.4)$ & $402(63.2)$ & 6253 & \\
\hline 1 & $3603(31.7)$ & $163(25.6)$ & 3766 & \\
\hline 2 & $1362(12)$ & $56(8.8)$ & 1418 & \\
\hline 3 & $418(3.7)$ & $11(1.7)$ & 429 & \\
\hline $4+*$ & $\geq 142$ & $\leq 5$ & 147 & \\
\hline Health authority of residence & & & & $p=0.16$ \\
\hline Interior health & $2182(19.2)$ & $104(16.4)$ & 2286 & \\
\hline Fraser health & $2882(25.3)$ & $174(27.4)$ & 3056 & \\
\hline Vancouver coastal health & $2789(24.5)$ & $169(26.6)$ & 2958 & \\
\hline Island health & $2805(24.7)$ & $143(22.5)$ & 2948 & \\
\hline Northern health & $710(94.04)$ & $45(5.96)$ & 755 & \\
\hline \multicolumn{5}{|l|}{ Time to finding new MSOC } \\
\hline$<6$ months & $3247(28.5)$ & & & \\
\hline $6-12$ months & $2924(25.7)$ & & & \\
\hline $12-18$ months & $2531(22.3)$ & & & \\
\hline 18-24 months & $970(8.5)$ & & & \\
\hline 24-30 months & $701(6.2)$ & & & \\
\hline 30-36 months & $357(3.1)$ & & & \\
\hline$>36$ months & $647(5.7)$ & & & \\
\hline
\end{tabular}

*Precise numbers and percentages not included due to small cell counts (to preserve anonymity)

whose MSOC retired, we computed time in days between the last visit with them, and the first visit with a new primary care physician who eventually became the patient's new MSOC.
We conducted descriptive analyses to determine whether patients whose MSOC physician retired are statistically different from those whose physician did not retire (according to age, sex, income quintile and 


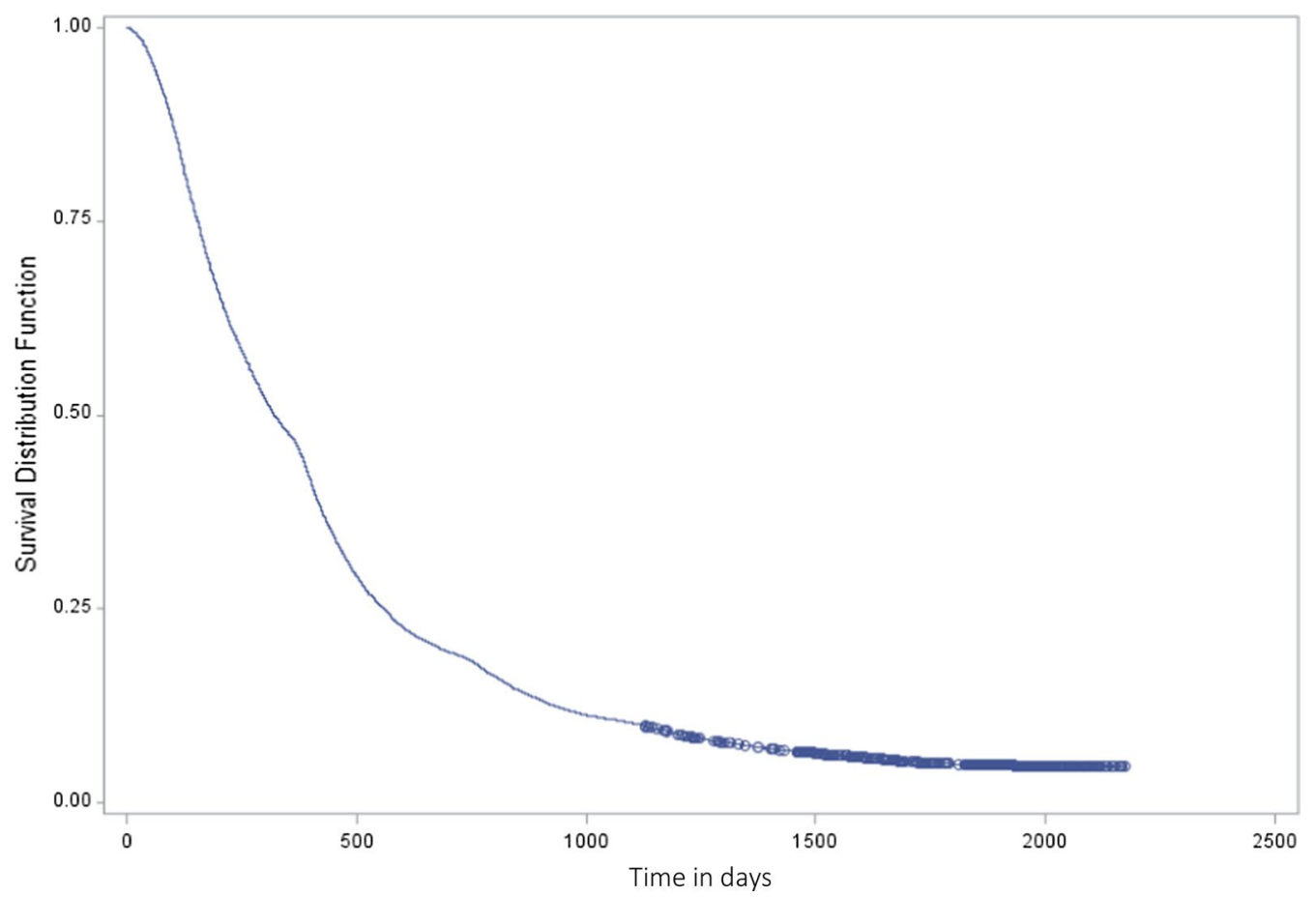

Fig. 2 Time to finding a new MSOC among patients of retiring primary care practitioners

morbidity level) using Chi-square and Fisher's exact tests. We used the same approach to compare individuals who found a new MSOC with those who did not.

\section{Exposures}

We used multivariable Cox proportional hazards regression to determine the association between demographic factors, age, sex, socioeconomic status, location and aggregated clinical groups, and time to finding a new primary care physician after their original physician retired. We produce survival analysis graphs stratified by sex, age group, morbidity level, and income quintile, using the date of physician retirement as time zero. We used SAS statistical software to complete our analyses.

\section{Results}

We identified 463,044 patients who were continuously registered with MSP between 2005/2006 and 2011/2012 and who had the same MSOC for 2005/2006 and 2006/2007 (Fig. 1). Of these, 12,013 patients had an MSOC who was over age 50 at the beginning of the study period, and who ceased clinical practice in either $2007 / 2008$ or $2008 / 2009$ ( $N=68$ unique physicians) (Table 1$).{ }^{1}$ A majority of the patients of retiring

\footnotetext{
${ }^{1}$ This implies an average of 173 MSOC patients per retiring physician. The fact that this number is small likely reflects the fact that the MSOC measure requires three visits per year, with the same physician providing at least two of those visits.
}

physicians were over age 50 (69.3\%). Just over half were women (54.5\%). Patients were equally distributed across the five income quintiles. Half had no major ADGs (52.1\%) while $4.8 \%$ had three or more.

The vast majority (94.3\%) of the patients found a new MSOC between when their original MSOC retired (in $2007 / 2008-2008 / 2009$ ) and the end of the study period $(2011 / 2012)$ (Table 2). However, $45.8 \%$ took longer than one year, and $5.7 \%$ still had not found one 36 months after their original MSOC retired (Fig. 2).

Compared to patients who successfully found a new MSOC, those who did not were more likely to be in the younger age categories (for example 18.7\% versus 3.6\% under age $20, p<0.0001)$, male $(51.7 \%$ versus $45.1 \%$, $p<0.0001$ ) and have fewer major ADGs (for example $63.2 \%$ versus 51.4 had no major ADGs, $p<0.0001$ ). They were also more likely to be in the lowest income quintile (28.8\% versus $20.5 \%, p<0.0001)$.

In the time-dependent analysis and controlling for the effect of other factors, men had lower adjusted rates of finding a new MSOC compared to women (HR 0.92, 95\% CI 0.88-0.95) (Table 3, Fig. 3). We observed a clear trend by age group, with individuals in the oldest age categories having the highest likelihood of finding a new MSOC compared to those in the lowest age category (e.g., individuals $70-79$ HR 3.26, 95\% CI 2.91-3.65). A patient's regional health authority of residence was also associated with the odds of finding a new MSOC, with individuals 
Table 3 Adjusted hazard ratios from multivariable Cox regression

\begin{tabular}{|c|c|c|c|}
\hline & Hazard ratio & $95 \% \mathrm{Cl}$ & $P$-value \\
\hline \multicolumn{4}{|l|}{ Patient characteristics } \\
\hline Male sex & 0.92 & $0.88-0.95$ & $<0.0001$ \\
\hline \multicolumn{4}{|l|}{ Age group (reference $=<20$ ) } \\
\hline $20-29$ & 1.18 & $1.02-1.36$ & 0.028 \\
\hline $30-39$ & 1.47 & $1.29-1.66$ & $<0.0001$ \\
\hline $40-49$ & 1.85 & $1.65-2.06$ & $<0.0001$ \\
\hline $50-59$ & 2.37 & $2.12-2.64$ & $<0.0001$ \\
\hline $60-69$ & 2.92 & $2.61-3.26$ & $<0.0001$ \\
\hline 70-79 & 3.26 & $2.91-3.65$ & $<0.0001$ \\
\hline$>=80$ & 3.04 & $2.68-3.44$ & $<0.0001$ \\
\hline \multicolumn{4}{|c|}{ Health authority of residence (reference $=$ interior health) } \\
\hline Fraser health & 0.90 & $0.84-0.97$ & 0.008 \\
\hline Vancouver coastal & 0.73 & $0.67-0.78$ & $<0.0001$ \\
\hline Vancouver Island & 0.86 & $0.80-0.93$ & $<0.0001$ \\
\hline Northern health & 0.95 & $0.85-1.06$ & 0.358 \\
\hline \multicolumn{4}{|c|}{ Income quintile (reference $=1$, lowest) } \\
\hline 2 & 1.05 & $0.99-1.12$ & 0.098 \\
\hline 3 & 1.04 & $0.98-1.11$ & 0.187 \\
\hline 4 & 1.03 & $0.97-1.10$ & 0.302 \\
\hline 5 (highest) & 1.07 & $1.00-1.13$ & 0.036 \\
\hline \multicolumn{4}{|l|}{ Major ADGs (reference $=0$ ) } \\
\hline 1 & 1.05 & $1.01-1.1$ & 0.028 \\
\hline 2 & 1.08 & $1.02-1.15$ & 0.015 \\
\hline 3 & 1.20 & $1.08-1.33$ & 0.001 \\
\hline $4+$ & 1.19 & $1.00-1.41$ & 0.052 \\
\hline Regional primary care supply & 1.00 & $0.98-1.01$ & 0.470 \\
\hline \multicolumn{4}{|l|}{ Physician characteristics } \\
\hline Male sex & 0.90 & $0.85-0.96$ & 0.001 \\
\hline \multicolumn{4}{|l|}{ Age group (reference $=<55$ ) } \\
\hline $56-59$ & 1.28 & $1.19-1.38$ & $<0.0001$ \\
\hline $60-64$ & 1.36 & $1.28-1.45$ & $<0.0001$ \\
\hline $65-69$ & 1.34 & $1.24-1.44$ & $<0.0001$ \\
\hline $70-74$ & 1.25 & $1.15-1.35$ & $<0.0001$ \\
\hline $75+$ & 1.35 & $1.23-1.49$ & $<0.0001$ \\
\hline Trained in Canada (vs international) & 1.03 & $0.97-1.08$ & 0.356 \\
\hline
\end{tabular}

located in two of the health authorities having less success with finding a new physician (Vancouver Coastal Health: HR 0.73, 95\% CI 0.67-0.78; Vancouver Island: HR $0.86,0.80-0.93$ ); however regional primary care physician supply had no effect (HR 1.0, 95\% CI 0.98-1.01).

Rates of finding a new MSOC were positively associated with morbidity, with individuals having 3 , or 4+ADGs in particular having higher rates (3 Major ADGs: HR 1.20, 95\% CI 1.08-1.33; 4+ Major ADGs: HR $1.19,1.00-1.41)$. Compared with the lowest income quintile, patients in the highest income quintile had small but statistically significantly greater likelihood of finding a new MSOC (HR 1.07, 95\%CI 1.00-1.13).

Physician characteristics also influenced time to finding a new MSOC. Patients whose original (retired) physician was male (HR 0.90, $p=0.001$ ) had lower adjusted rates of finding a new MSOC, while patients whose retiring physicians were in any but the youngest age category had significantly higher rates (e.g., age $75+$ HR 1.35, $p<0.0001$ ). We observed no difference between physicians who trained internationally and those who trained in Canada.

\section{Discussion}

To our knowledge, this is the first study that examines patients' primary care interactions in the period following the retirement of their primary care physician, using a population-based approach. We found that while the vast majority of patients do go on to find a new MSOC, that process can take considerable time. Six percent of our sample had not found a family physician 36 months after the retirement of their original MSOC. Eighteen percent took between 18 and 36 months.

Older patients and those with more significant morbidity had higher rates of finding a new primary care physician, and found one more quickly, consistent with the suggestion that younger, healthier patients are less likely to make seeking out a new, consistent, source of primary care a priority, even within this cohort of patients with three or more visits per year [52]. Individuals in the lowest income quintile were somewhat less likely to find a new MSOC. While at first glance this may seem to be an artifact of fewer physicians providing longitudinal primary care in low-income areas, this relationship persisted in the Cox regression where regional primary care supply was accounted for. This finding raises questions about whether marginalized populations are less likely to seek out a new family physician, or less successful at doing so. There is evidence suggesting that the likelihood of having at least one primary care visit is independent of income $[53,54]$; however, individuals who have low socioeconomic status are more likely to face discrimination when seeking out an appointment with a new primary care physician [55], suggesting that they still have relatively more challenges with accessing primary care may compared to individuals in higher income groups.

We found significant differences in the rates of individuals finding a new MSOC across regional health authorities, even when we accounted for differences in regional primary care capacity. Individuals in the largest (by population) and most urban health authority had the lowest time-adjusted rates of finding a new MSOC. On the surface, this finding seems contrary to the body of evidence suggesting that accessibility challenges are more salient 


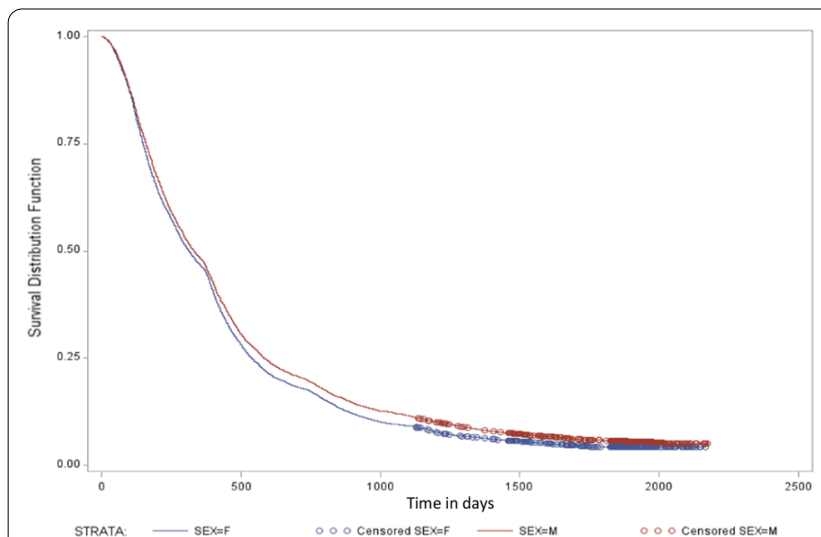

a) Sex stratified

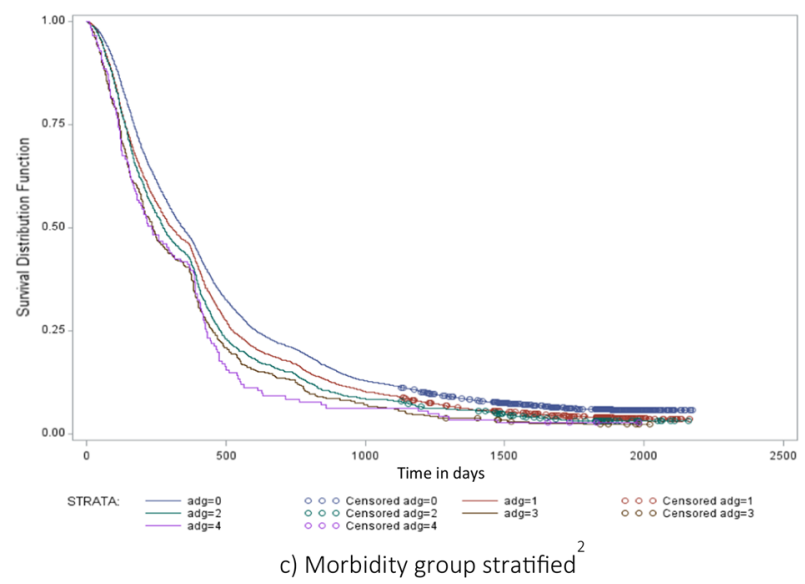

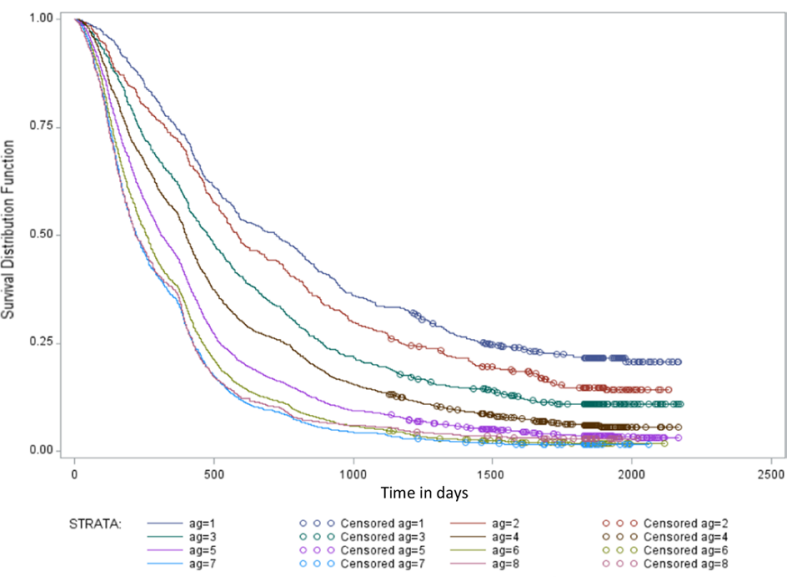

b) Age group stratified ${ }^{1}$

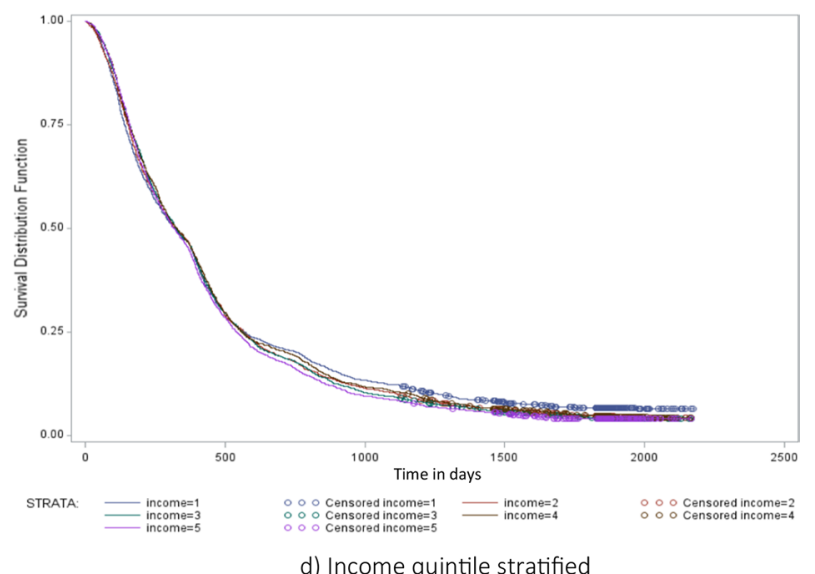

d) Income quintile stratified

Fig. 3 Time to finding to a new MSOC among patients of retiring primary care practitioners (stratified by sex, age, morbidity and income quantile)

in rural areas compared to urban ones; however, it may relate to greater access to walk-in clinics in urban centers in particular, and to the role these clinics play in shaping access to longitudinal primary care.

Several organizations have tools and programs designed to assist physicians with the process of retirement, one element of which is ensuring a smooth transition for their patients (for example $[56,57]$ ). For example the B.C. General Practice Services Committee, through their broader GP for Me Initiative, offers a program that attempts to match new-to-practice physicians with retiring general practitioners, while also providing business coaching and support [57]. To our knowledge, however, neither this program nor any of the other supports offered, have been evaluated in terms of their ability to assist physicians with retirement, or ensure an easy transition for their patients.

Furthermore, given the more general 'taut' primary care supply situation in the province, retiring physicians' ability to find younger primary care practitioners who are able to take on large numbers of new patients is likely to be an incredible challenge. Connection to a centralized waiting list is one potential solution that is being trialed in a number of Canadian provinces [58]. While there are wide differences in implementation of these lists, a consistent challenge among them is extensive waiting periods due to demand for attachment that far outstrips supply [59]. Lower rates of attachment of vulnerable patients, such as those with harmful substance use issues, mental health concerns, or chronic diseases are also a known concern with some implementations of this type of management strategy $[59,60]$.

\section{Limitations}

While we believe that the use of administrative payment data is a strength of this study, allowing for a population-based, comprehensive analysis, the approach is not without its challenges. For example, our measure of retirement was necessarily blunt. The chosen data sources provide no ability to determine whether patients of retiring physicians had been looking for or transitioning to new MSOC before their original physician ceased 
clinical practice. Our measure of time to finding a new MSOC would certainly be an underestimate in such cases.

Our measure of attachment, majority source of care, is also relatively crude. It requires a minimum of three annual visits, which means that healthier patients who interact with the health system less often are underrepresented. This is necessary to ensure more accurate assignment of physicians to patients and also focuses in on a population that may be most impacted by any changes in primary care interactions surrounding retirement. The MSOC measure does not, however, account for patients who are seen within a team-based model of practice, though these models were rare in $\mathrm{BC}$ in the time period represented.

Our patient cohort includes only individuals who were continuously registered with BC MSP for the full study period. Thus, patients who died or moved out of province were excluded. This may introduce an element of selection bias in that some of the sickest patients were likely to have been excluded.

The use of the Alternative Payments Database (APD) ensures that physicians who move from FFS to an alternative funding model are not misclassified as having retired. However, we have no ability to track individual patient interactions in the APD. This limitation artificially reduces the number of visits patients might have with a particular physician, in turn reducing the attachment (MSOC) rate. However, given that few physicians tend to transition to non-FFS contracts towards the end of their practice careers [61], we do not expect this would have affected our results. Furthermore, the APD was only available for analysis through $2011 / 2012$, preventing us from assessing trends in more recent years.

As this research was grounded in administrative data, we cannot comment on patient perspectives or experiences with physician retirement or subsequent accessibility or continuity issues. This remains a critical knowledge gap and one that should be explored in future studies, with a particular focus on potential equity considerations for vulnerable populations.

\section{Conclusion}

Primary care physician retirements represent a potential challenge to accessibility and continuity of care for patients, particularly in light of apparent systemic shortages in many provinces. We find that, on average, patients take more than a year to find a new regular source of primary care following the retirement of their original physician. Existing programs intended to smooth the retirement transition for physicians and for patients should be evaluated; however, we expect their efficacy is likely to be hampered by broader accessibly challenges. These can only be addressed through initiatives designed to increase capacity for longitudinal, community-based primary care.

\section{Abbreviations}

ADGs: Aggregated diagnostic groupings; APD: Alternative payments database; BC: British Columbia; FFS: Fee-for-service; MSOC: Majority source of care; MSP: Medical services plan.

\section{Acknowledgements}

Not applicable.

\section{Authors' contributions}

$\mathrm{LH}, \mathrm{MA}, \mathrm{ML}, \mathrm{KM}, \mathrm{MB}$, and $\mathrm{ML}$ co-conceptualized the study. $\mathrm{LH}, \mathrm{MA}$, and $\mathrm{ML}$ designed the analytic strategy. $\mathrm{LH}$ and MA drafted the manuscript and incorporated coauthor feedback. KM, MB and ML provided feedback on data analyses and manuscript development at all stages. LC cleaned and analyzed all data. All authors read and approved the final manuscript.

\section{Funding}

This study was funded by a Canadian Institutes of Health Research Operating Grant (FRN 104086).

\section{Availability of data and materials}

The data that support the findings of this study are available from Population Data $B C$ but restrictions apply to the availability of these data, which were used under license for the current study, and so are not publicly available. Permission to access these data can be obtained from the data holders pending a completed data access request and ethics approval from the appropriate research ethics board. All inferences, opinions, and conclusions drawn in this manuscript are those of the authors, and do not reflect the opinions or policies of the Data Stewards.

\section{Declarations}

\section{Ethics approval and consent to participate}

Ethics approval was waived by the University of British Columbia Behavioural Research Ethics Board (certificate number H09-02977). This study is a secondary analysis of de-identified, population level administrative data and therefore consent to participate is not applicable.

Consent for publication

Not applicable.

\section{Competing interests}

The authors declare that they have no competing interests.

\section{Author details}

${ }^{1}$ Faculty of Health Sciences, Simon Fraser University, Blusson Hall, Room 11300 , 8888 University Drive, Burnaby, BC V5A 156, Canada. ${ }^{2}$ Centre for Health Services and Policy Research, School of Population and Public Health, University of British Columbia, 201-2206 East Mall, Vancouver, BC V6T 1Z3, Canada.

Received: 26 October 2020 Accepted: 13 July 2021

Published online: 23 July 2021

\section{References}

1. Pong RW, Lemire F, Tepper J. Physician retirement in Canada: what is known and what needs to be done. In: 10th International Medical Workforce Conference, Vancouver BC; 2007.

2. Pong RW. Putting away the stethoscope for good? Toward a new perspective on physician retirement spending and health workforce. 2011. 
3. Chan BTB. From perceived surplus to perceived shortage: what happened to Canada's physician workforce in the 1990s? Ottawa, ON: Canadian Institute for Health Information; 2002.

4. Sullivan P. Concerns about size of MD workforce, medicine's future dominate CMA annual meeting. CMAJ. 1999;161:561-2.

5. Collier R. Doctors call for plan to curb physician shortage. CMAJ Can Med Assoc J. 2008;178(4):384

6. Tyrrell L, Dauphinee D. Task force in physician supply in Canada. Ottawa ON: Canadian Medical Forum Task Force, Association of Canadian Medical Colleges; 1999.

7. Lam K, Arnold CG, Savage RD, Stall NM, Zhu L, Wu W, et al. Does physician retirement affect patients? A systematic review. J Am Geriatr Soc. 2020;68(3):641-9.

8. Sabety AH, Jena AB, Barnett ML. Changes in health care use and outcomes after turnover in primary care. JAMA Intern Med. 2021;181(2):186-94.

9. Choudhry NK. Systematic review: the relationship between clinical experience and quality of health care. Ann Intern Med. 2005;142(4):260.

10. Chan B, Anderson GM, Theriault M-E. Patterns of practice among older physicians in Ontario. CMAJ. 1998;159(9):1101-6.

11. Carthy P, Harvey I, Brawn R, Watkins C. A study of factors associated with cost and variation in prescribing among GPs. Fam Pract. 2000;17(1):36-41.

12. Freiman MP. The rate of adoption of new procedures among physicians: the impact of specialty and practice characteristics. Med Care. 1985;23(8):939-45.

13. Young MJ, Fried LS, Eisenberg J, Hershey J, Williams S. Do cardiologists have higher thresholds for recommending coronary arteriography than family physicians? Health Serv Res. 1987;22(5):623-35.

14. Treeson D. Health Care in the Borderland. Perspect Biol Med. 2003;1 (46):567-78.

15. Shahady E. A physician's quide to the art of successful retirement. 2004. https://www.retirementfammed.com/uploads/1/0/2/7/10277276/retir ement_book web_version.pdf. Accessed 30 Mar 2021.

16. Statistics Canada. Primary health care providers, 2017. https://www150. statcan.gc.ca/n1/pub/82-625-x/2017001/article/54863-eng.htm. Accessed 1 Nov 2019

17. Baker DW, Stevens CD, Brook RH. Regular source of ambulatory care and medical care utilization by patients presenting to a Public Hospital Emergency Department. J Am Med Assoc. 1994;271(24):1909-12.

18. Rask KJ, Williams MV, Parker RM, Mcnagny SE. Obstacles predicting lack of a regular provider and delays in seeking care for patients at an Urban Public Hospital. J Am Med Assoc. 1994:271(24):1931-3.

19. Schoen C, Osborn R, Huynh PT, Doty M, Davis K, Zapert K, et al. Primary care and health system performance: adults' experiences in five countries. Health Aff (Millwood). 2004;W4:487-503.

20. Lowe RA, Localio AR, Schwarz DF, Williams S, Tuton LW, Maroney S, et al. Association between primary care practice characteristics and emergency department use in a Medicaid managed care organization. Med Care. 2005;43(8):792-800.

21. Cabana MD, Jee SH. Does continuity of care improve patient outcomes? J Fam Pract. 2004;53(12):974-80.

22. Van Walraven C, Oake N, Jennings A, Forster AJ. The association between continuity of care and outcomes: a systematic and critical review. J Eval Clin Pract. 2010;16(5):947-56.

23. Fan VS, Burman M, McDonell MB, Fihn SD. Continuity of care and other determinants of patient satisfaction with primary care. J Gen Intern Med. 2005;20(3):226-33.

24. Mclsaac WJ, Fuller-Thomson E, Talbot Y. Does having regular care by a family physician improve preventive care? Can Fam Phys. 2001;47:70-6.

25. Starfield B. Is primary care essential? Lancet. 1994:344(8930):1129-33.

26. Weiss GL. Patient satisfaction with primary medical care: evaluation of sociodemographic and predispositional factors. Med Care. 1988. https:// doi.org/10.1097/00005650-198804000-00007.

27. Statistics Canada. Access to a regular medical doctor, 2014. 2015 http:// www.statcan.gc.ca/pub/82-625-x/2015001/article/14177-eng.htm.

28. Freeman T, Brown JB, Reid G, Stewart M, Thind A, Vingilis E. Patients' perceptions on losing access to FPs: qualitative study. Can Fam Phys Med Fam Can. 2013;59(4):e195-201.

29. CBC News. Wave of retiring doctors expected to worsen doctor shortage in B.C.-British Columbia-CBC News. 2016. http://www.cbc.ca/news/ canada/british-columbia/doctor-shortage-bc-retiring-doctors-1.3553015.
30. Fayerman P, Morton B. Wanted: Doctors to fill 667 vacancies in B.C. |Vancouver Sun. 2016http://vancouversun.com/news/local-news/wanteddoctors-to-fill-667-vacancies-in-b-c.

31. Greer D. Is there a doctor in the house? |The Tyee. 2006.

32. Society of General Practitioners of British Columbia. Family Practice Recommendations for British Columbia's Health Care System. 2007.

33. Ontario Medical Association. Closing a practice: a guide for physicians. No date. https://www.oma.org/uploadedfiles/oma/media/public/1_windi ngdownapractice.pdf. Accessed 30 Mar 2021.

34. Maine Medical Association. Physician's guide to closing practice. 2014. https://www.mainemed.com/sites/default/files/content/Closing\%20Pra ctice\%20Guide\%20FINAL\%206.2014.pdf. Accessed 30 Mar 2021.

35. College of Physicians and Surgeons of British Columbia. Professional standards and guidelines: leaving practice. 2021. https://www.cpsbc.ca/ files/pdf/PSG-Leaving-Practice.pdf. Accessed 30 Mar 2021.

36. Vancouver Division of Family Practice. How to retire guide. 2016. https:// divisionsbc.ca/sites/default/files/CMSMedia_Retrieved/How\%20to\% 20Retire\%20Final\%20April\%2013th.pdf. Accessed 30 Mar 2021

37. Wakeford R, Roden M, Rothman A. General practitioners' retirement plans and what influences them. Br Med J Clin Res Ed. 1986;292(6531):1307-9.

38. Onyura B, Bohnen J, Wasylenki D, Jarvis A, Giblon B, Hyland R, et al. Reimagining the self at late-career transitions: how identity threat influences academic physicians' retirement considerations. Acad Med. 2015;90(6):794-801.

39. Anderson BL, Hale RW, Salsberg E, Schulkin J. Outlook for the future of the obstetrician-gynecologist workforce. Am J Obstet Gynecol. 2008;199(1):88.e1-88.

40. Fletcher SL, Schofield DJ. The impact of generational change and retirement on psychiatry to 2025. BMC Health Serv Res. 2007. https://doi.org/ 10.1186/1472-6963-7-141.

41. Reuben DB, Silliman RA. Lessons from elderly physicians: reflections on practice, changes in medicine, and retirement. J Appl Gerontol. 1988;7(1):49-59.

42. Silver MP, Hamilton AD, Biswas A, Warrick NI. A systematic review of physician retirement planning. Hum Resour Health. 2016;14(1):67.

43. Peckham A, Ho J, Marchildon G. Policy innovations in primary care across Canada. North American observatory on health systems and policies; 2018, p. 63. https://ihpme.utoronto.ca/wp-content/uploads/2018/04/ NAO-Rapid-Review-1_EN.pdf. Accessed 13 Jan 2020.

44. British Columbia Ministry of Health [Creator]. Consolidation file (MSP Registration \& Premium Billing). V2. Population Data BC [publisher]; 2012.

45. British Columbia Ministry of Health [Creator], British Columbia Ministry of Health. Medical Services Plan (MSP) Payment Information File. V2. Population Data BC; 2013.

46. Canadian Institute for Health Information [Creator]. Discharge Abstract Database (Hospital Separations). Population Data BC; 2011.

47. Johns Hopkins University. About the ACG System. 2012. http://www. acg.jhsph.org/index.php?option=com_content\&view=article\&id=46\& Itemid=366. Accessed 6 Dec 2013.

48. Health Services Research and Development Centre at Johns Hopkins University. The Johns Hopkins ACG System: Technical Reference Guide, Version 10.0. Baltimore, MD; 2011.

49. College of Physicians and Surgeons of BC [Creator]. Medical Services Plan Physician Database. Population Data BC [publisher]. 2013.

50. Hedden L, Lavergne MR, McGrail KM, Law MR, Cheng L, Ahuja MA et al. Patterns of physician retirement and pre-retirement activity: a population-based cohort study. CMAJ. 2017. https://doi.org/10.1503/ cmaj.170231.

51. Hedden L, Lavergne MR, McGrail KM, Law MR, Cheng L, Ahuja MA, et al. Will the real physician retirees please stand up? Healthc Policy. 2018;14(2):32-9.

52. Hay C, Pacey M, Bains N, Ardal S. Understanding the unattached population in ontario: evidence from the primary care access survey (PCAS). Healthc Policy Polit Sante. 2010;6(2):33-47.

53. Dunlop S, Coyte PC, Mclsaac W. Socio-economic status and the utilisation of physicians' services: results from the Canadian National Population Health Survey. Soc Sci Med 1982. 2000;51(1):123-33.

54. Blackwell DL, Martinez ME, Gentleman JF, Sanmartin C, Berthelot J-M. Socioeconomic status and utilization of health care services in Canada and the United States: findings from a binational health survey. Med Care. 2009;47(11):1136-46 
55. Olah ME, Gaisano G, Hwang SW. The effect of socioeconomic status on access to primary care: an audit study. CMAJ. 2013;185(6):E263-9.

56. College of Physicians and Surgeons of British Columbia. Professional Standards and Guidelines: Leaving Practice. 2009.

57. Vancouver Division of Family Practice. How to retire. 2016.

58. Breton M, Green M, Kreindler S, Sutherland J, Jbilou J, Wong ST, et al. A comparative analysis of centralized waiting lists for patients without a primary care provider implemented in six Canadian provinces: study protocol. BMC Health Serv Res. 2017:17(1):60

59. Breton M, Wong ST, Smithman MA, Kreindler S, Jbilou J, Sutherland J, et al. Centralized waiting lists for unattached patients in primary care: learning from an intervention implemented in seven Canadian Provinces. Healthc Policy Polit Sante. 2018;13(4):65-82.
60. Breton M, Brousselle A, Boivin A, Roberge D, Pineault R, Berbiche D. Who gets a family physician through centralized waiting lists? BMC Fam Pract. 2015;16(1):10

61. Hedden L. Beyond full-time equivalents: gender differences in activity and practice patterns for BC's primary care physicians. University of British Columbia; 2015.

\section{Publisher's Note}

Springer Nature remains neutral with regard to jurisdictional claims in published maps and institutional affiliations.
Ready to submit your research? Choose BMC and benefit from:

- fast, convenient online submission

- thorough peer review by experienced researchers in your field

- rapid publication on acceptance

- support for research data, including large and complex data types

- gold Open Access which fosters wider collaboration and increased citations

- maximum visibility for your research: over $100 \mathrm{M}$ website views per year

At BMC, research is always in progress.

Learn more biomedcentral.com/submissions 